\title{
Nutritional Status and Health-Related Quality of Life among Knee and Hip Osteoarthritis Patients under Rehabilitation Care in Kuala Nerus, Terengganu, Malaysia
}

\author{
Zamri NAA', BHSc, Harith S', PhD, Mat-Hassan N², PhD, Ong YQ'1, BHSc \\ 'Faculty of Health Sciences, Universiti Sultan Zainal Abidin, Kuala Nerus, Malaysia \\ ${ }^{2}$ Faculty of Medicine, Universiti Sultan Zainal Abidin, Kuala Terengganu, Malaysia
}

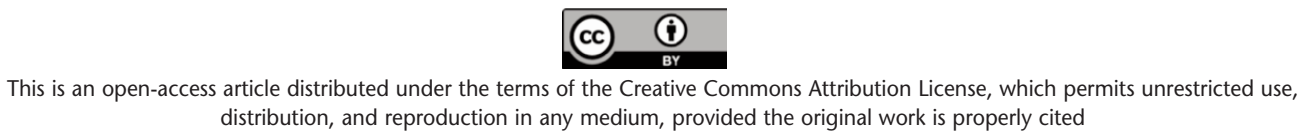

distribution, and reproduction in any medium, provided the original work is properly cited

Date of submission: 04th April 2020

Date of acceptance: 20th April 2021

\begin{abstract}
Introduction: The World Health Organisation (WHO) has estimated that $80 \%$ of people with osteoarthritis (OA) have movement limitations while $25 \%$ of them cannot perform their major daily activities, thus resulting in a decline of their nutritional status and quality of life (QOL). Therefore, this study aimed to compare the nutritional status and healthrelated quality of life (HRQOL) of OA patients between gender and age group.

Material and methods: A cross-sectional study was conducted on $131 \mathrm{OA}$ patients in Rehabilitation Health Organisation, Terengganu. Socio-demographic, clinical, lifestyle histories, 24-hour dietary intake and HRQOL were assessed using a structured questionnaire.

Results: Knee and/or hip OA patients recruited consisted of $19.1 \%$ of men and $80.9 \%$ of women collectively with a mean age of 61.81 (9.28) years ranging from 38 to 83 years. The percentages of underweight, normal, overweight, and obese patients were $1.5 \%, 12.2 \%, 36.7 \%$, and $49.6 \%$, respectively. Further assessment of HRQOL showed that the highest mean score was obtained by the social functioning (SF) domain of 41.25 (27.16), while the mental domain scored the least mean score of 21.15 (20.92). In terms of gender breakdown, the males had significantly greater weight and height but lower body fat (BF) compared to their female counterparts, as well as a significantly higher energy, carbohydrate and protein intake. According to the age group, patients aged $<60$ years had significantly greater weight, height, and $\mathrm{BF}$ than those aged $\geq 60$ years.

Conclusion: This study is an important baseline reference for proper OA management and prevention by providing crucial nutritional status and HRQOL information.
\end{abstract}

Keywords:

nutritional status, health-related quality of life, osteoarthritis

\section{INTRODUCTION}

Osteoarthritis (OA) is a degenerative musculoskeletal disorder distinguished by gradual articular cartilage degradation, osteophyte formation, and subsequent joint space narrowing. The elderly is the most susceptible population affected by this problem; as the population ages, its prevalence rises and subsequently exerts a huge economic burden on the society ${ }^{2}$. A study predicted that in 2010, 3.8\% and $0.85 \%$ of the global population would suffer from knee and hip OA, respectively. These figures accounted for the 11th and 38th largest worldwide morbidity as measured by the disability-adjusted life years (DALYS) ${ }^{3}$. Accordingly, the DALYS of OA has been found to be higher than colon/rectum cancer (44th), breast cancer (47th), and Alzheimer disease (49th) .

OA prevalence is increasing due to the growing size of the ageing population in developed and developing countries alike, as well as an increase in risk factors leading to the disease, particularly obesity and sedentary lifestyle ${ }^{5}$. Furthermore, it is associated with an increased mortality, either directly or due to its associated comorbidities. Compared to the general population, people with $\mathrm{OA}$ are associated with a $55 \%$ of increase in all mortality causes due to cardiovascular disease ${ }^{6}$. Malaysia is sharing the same experience ${ }^{7}$ in which Malaysian people are living longer, recording an average life expectancy level similar to other upper-middle-income countries. According to the National Health and Morbidity Survey (NHMS) 2015, the prevalence of overweight among adults in Malaysia was $30.0 \%$ while obesity recorded $17.7 \%$ of prevalence ${ }^{8}$. Therefore, Malaysians are associated with a high chance of increased OA prevalence due to these reasons.

In general, this disease exerts a huge impact on daily life activities, which leads to more vulnerability and dependency

Corresponding Author: Sakinah Harith, Faculty of Health Sciences, Universiti Sultan Zainal Abidin, Kampus Gong Badak, Gong Badak, 21300 Kuala Nerus, Terengganu Darul Iman, Malaysia

Email: sakinahharith72@gmail.com 
and thus causing a deterioration of welfare and quality of life (QOL) among the elderly'. WHO has reported that approximately $80 \%$ of people with OA will have limitations in their movement while $25 \%$ cannot perform their major daily activities, resulting in a significant QOL reduction ${ }^{10}$. Besides, alteration in body composition such as reduction of muscle mass and accumulation of body fat observed in the elderly can further influence their nutritional status ${ }^{11}$. Therefore, this study aims to determine the nutritional status and health-related quality of life (HRQOL) of OA patients in Kuala Nerus, Terengganu, Malaysia. Besides, the anthropometry data, dietary intake, and HRQOL information obtained were compared between the gender and age groups accordingly. It is hypothesised that there was a significant difference in nutritional status and HRQOL between the gender and age groups.

\section{MATERIALS AND METHODS}

A cross-sectional observational study utilising the universal sampling method was conducted from May 2017 to December 2018 among the knee and/or hip OA patients, which were referred from and undertaking follow-up appointments in the Rehabilitation Health Organisation (RHO) located in Kuala Nerus, Terengganu. The ethical approval was obtained from the Medical Research and Ethics Committee (NMRR-16-1937-30162) and Universiti Sultan Zainal Abidin (UniSZA) Human Research Ethics Committee (UHREC) (UniSZA C/1/uhrec/628-1). An information sheet was given to each patient together with a standard consent form before the study commencement.

The sample size consisted of 128 subjects, which was calculated using the $\mathrm{G}^{*}$ Power 3.1.9.4 software according to the effect size at $0.5^{7}$ and confidence level at $95 \%$ using two mean formula. After considering a drop-out rate at 10\%, a total of 142 patients who met the inclusion criteria were recruited in this study. The inclusion criteria required knee and/or hip OA patients from both sexes, who were diagnosed with either clinical or radiographic evidence with the disease by a medical doctor based on the International Classification of Diseases (ICD) or American College Rheumatology Criteria $^{12}$. In contrast, the exclusion criteria detailed patients with a mental disorder or were terminally ill. Those with degenerative diseases that could affect their QOL such as cancer, heart disease, Parkinson's disease, and more were also excluded.

This study utilised a standardised and structured questionnaire containing several parts, namely: (1) sociodemographic, (2) clinical and lifestyle histories, (3) dietary intake, and (4) Osteoarthritis Knee Hip Quality of Life (OAKHQOL) questionnaire. The patients were interviewed by the researchers, which took around 30 to 45 minutes per session. The socio-demographic part consisted of questions on respondent age, gender, race, marital status, educational level, employment status, household income, and family history of OA.

Next, the information on clinical characteristics included the type of OA, disease duration, treatment performed, and the amount and type of comorbidities. Meanwhile, the lifestyle history asked comprised of a few aspects, such as physical activity involvement; consumption of fruits, vegetables, and milk according to the Malaysian Dietary Guidelines (2010); and dietary supplements (i.e. type, frequency, and amount of intake). Dietary intake was recorded for three days (two weekdays and one day of the weekend) by using 24-hour dietary recall.

Furthermore, the HRQOL was measured by using the Malay version of OAKHQOL questionnaire, which had previously undergone the process of translation and validation and contained 31 items $^{13}$. The questionnaire consisted of five domains with a respective Cronbach's alpha value between 0.865 and 0.933 each, while the factor loading of each item score was above 0.65 . Each item was assessed on a Likert scale ranging from zero (not at all) to 10 (a great deal). The score of each domain was multiplied by 10 and presented as a mean (i.e. divided by the number of each domain), which yielded the maximum score of 100 for each domain.

Body weight was measured twice in light indoor clothing by using an electronic scale [TANITA model UM-050] to obtain the mean value, which was recorded to the nearest $0.1 \mathrm{~kg}$. Meanwhile, the height was measured twice using SECA 217 stadiometer [SECA, Germany] to obtain the mean value, which was recorded to the nearest $0.1 \mathrm{~cm}$. In contrast, an alternative height measurement to predict the height for knee and/or hip OA patients with hunchback was utilised instead of the conventional standing height measurement. Here, their height was estimated using the demi-span using age and gender-specific demi-span equations ${ }^{14}$. Accordingly, demispan was measured twice by using a measuring tape and recorded to the nearest $0.1 \mathrm{~cm}$ on the dominant or non-paretic arm, which was taken from the finger root between the middle and ring fingers to the midpoint of the sternal notch, with the palms facing forward. Then, Body Mass Index (BMI) was calculated by dividing the weight $(\mathrm{kg})$ by the squared value of height $(\mathrm{m})$. The patients were then classified accordingly as underweight $\left(<18.5 \mathrm{~kg} / \mathrm{m}^{2}\right)$, normal (18.5 to $24.9 \mathrm{~kg} / \mathrm{m}^{2}$ ), overweight $\left(25.0\right.$ to $\left.29.9 \mathrm{~kg} / \mathrm{m}^{2}\right)$, and obese $\left(>30.0 \mathrm{~kg} / \mathrm{m}^{2}\right)$.

Waist circumference (WC) was measured twice by using the SECA measuring tape to the nearest $0.1 \mathrm{~cm}$. Prior to the measurement, the patients were asked to stand erectly and breathe normally. The highest point of the hip bone and the bottom of the ribs were located by using the fingertips, whereby the measuring tape was placed between the two points and kept snug against the waist. Therefore, WC was recorded at the end of normal expiration, which was 
categorised accordingly as high-risk waistline $>102 \mathrm{~cm}$ for men and $>88 \mathrm{~cm}$ for women ${ }^{15}$. Meanwhile, the percentage of body fat (BF) was recorded using a weighing scale. Cut-off values of $25-31 \%$ for women and $18-25 \%$ for men were classified as acceptable, meanwhile values of $>31 \%$ for women and $>25 \%$ for men were considered as at risk.

The research data obtained were analysed using IBM Statistical Package for the Social Sciences (SPSS) for Windows version 22.0, whereby all data were entered, cleaned, and checked before data analysis was conducted. The normality of each variable was tested first to examine whether they met the normal distribution assumptions by using the Kolmogorov-Smirnov test. Next, non-parametric tests were used when the data were not normally distributed.

Descriptive statistics was applied to report the overall findings on the socio-demographic, clinical characteristics, lifestyle history, anthropometric measurement, dietary intake, and HRQOL elements accordingly. They were reported as either the mean (standard deviation) or median (interquartile range) for numerical variables or frequency and percentage for categorical variables.

Bivariate analysis for the parametric tests such as independent t-test was done on the data gathered, which were normally distributed. The independent t-test was used to compare the difference of two means between gender (i.e. male and female) and age category (i.e. $<60$ years and $\geq 60$ years) of the anthropometric measurement, dietary intake, and HRQOL parameters. The analysis was considered as significant at $\mathrm{p}<0.05$.

\section{RESULTS}

A total of $157 \mathrm{knees}$ and/ or hip OA patients who fulfilled the inclusion criteria were approached, whereby 22 patients were then excluded due to unwillingness to participate ( $\mathrm{n}=$ 12) and non-attendance for appointments $(n=10)$. Then, four patients were further excluded from the analysis due to missing values, resulting in a total of 131 (92.3\%) patients who were included in the final analyses.

The mean age of the patients was 61.81 (9.28) years and ranged from 38 years to 83 years. All patients who participated in this study were of Malay descent (100.0\%), whereby a majority of them aged $\geq 60$ years $(65.6 \%)$, were female $(80.9 \%)$, married $(54.9 \%)$, and had at least graduated their secondary level of education $(48.8 \%)$. Similarly, more than half of the patients were unemployed (79.4\%), thereby classified as housewife or pensioner, while most of them had a low household income $(90.8 \%)$ with an average household income of RM 1020.39 (RM1702.56).
The mean disease duration among the patients was 4.27 (4.68) years. Most of the patients (55.8\%) were diagnosed with knee and/or hip OA within one to five years, followed by $19.8 \%$ diagnosed within less than one year (i.e. at least three months). Furthermore, an almost similar proportion of patients had a family history of OA $(48.1 \%)$, while the remaining had no history of OA $(51.9 \%)$. An almost similar proportion of the patients had a prescribed treatment $(53.4 \%)$, while the remaining were those without treatment (44.6\%)The type of treatment undertaken by a majority of the patients were oral medication (44.3\%).

In terms of comorbidity, the proportion of patients who had at least one $(22.9 \%)$, two $(26.7 \%)$, and three comorbidities $(24.4 \%)$ was not too different. A total of $62.6 \%$ of the patients presented with hypertension, followed by $58.0 \%$ with hyperlipidaemia and $36.6 \%$ with diabetes mellitus. However, only $6.8 \%$ of the patients presented with other diseases, such as asthma and gastritis. Out of 131 patients, a total of $49.6 \%, 26.0 \%, 12.2 \%$, and $12.2 \%$ were thus diagnosed with bilateral knee OA, knee and hip OA, right knee OA, and left knee OA, respectively.

A majority of the patients had a sedentary lifestyle (84.7\%) and inadequate intake of vegetable $(87.0 \%)$, fruit $(87.8 \%)$, and milk (64.1\%) accordingly. In contrast, $35.9 \%$ of the patients subscribed to supplement intake, some examples of supplements being vitamin $\mathrm{C}$, vitamin B-complex, fish oil, Arabic gum, Cellmaxx $\left.{ }^{(}\right)$(i.e. Phenylethylamine, phycocyanin, polysaccharide, L-selectin ligand), Shaklee Vivix $($ (i.e. botanical beverage mix), and Pamoga juice $($ ) (i.e. beverage mix).

The anthropometric assessment was performed for the patients, with the findings presented in (Table I) (gender comparison) and (Table II) (age comparison) accordingly. The mean weight, height, BMI, WC, and BF values were $72.61(15.67) \mathrm{kg}, 154.06(7.26) \mathrm{cm}, 30.51$ (5.88) kg/m2, $98.89(11.28) \mathrm{cm}$, and $41.62(7.58) \%$, respectively. According to (Fig. 1), the percentage of underweight respondents was low (1.5\%), while $12.2 \%$ was of normal weight. Meanwhile, the percentages of overweight $(36.7 \%)$ and obese (49.6\%) were highly prevalent.

Table I shows that the males have significantly greater weight $(p=0.030)$ and height $(p=0.001)$ compared to the females. However, the females showed a significantly higher $\mathrm{BF}$ than the males $(\mathrm{p}=0.001)$. Meanwhile, BMI classification of the knee and/or hip OA patients according to gender found that the males had a higher percentage of overweight $(40.0 \%)$ but a lower percentage of obese $(32.0 \%)$ compared to female $(34.9 \%, 53.8 \%)$ as shown in (Fig. 1). Next, the WC and BF measurements showed that the males had a lower percentage of high-risk group $(40.0 \%, 84.0 \%)$, respectively compared to their female counterparts $(87.7 \%$, 99.0\%) (Fig. 2). 
Table I: Anthropometric measurements according to gender $(n=131)$

\begin{tabular}{|lccccc|}
\hline Characteristic & Male $(\mathbf{n}=\mathbf{2 5})$ & $\begin{array}{c}\text { Mean }(\mathrm{SD}) \\
\text { Female }(\mathbf{n}=\mathbf{1 0 6})\end{array}$ & Total $(\mathbf{n}=\mathbf{1 3 1})$ & Range & p-value $^{\mathrm{a}}$ \\
\hline Weight $(\mathrm{kg})$ & $79.15(18.16)$ & $71.06(15.67)$ & $72.61(15.67)$ & $34.4-130.0$ & $0.030^{*}$ \\
Height $(\mathrm{cm})$ & $164.37(5.16)$ & $151.62(5.28)$ & $154.06(7.26)$ & $139.3-173.0$ & $0.001^{*}$ \\
BMI (kg/m2) & $29.11(5.44)$ & $30.84(5.95)$ & $30.51(5.88)$ & $17.7-53.39$ & 0.187 \\
WC (cm) & $100.74(9.00)$ & $98.45(11.75)$ & $98.89(11.28)$ & $63.6-122.7$ & 0.363 \\
BF (\%) & $32.84(8.75)$ & $43.69(5.57)$ & $41.62(7.58)$ & $23.3-58.4$ & $0.001^{*}$ \\
\hline
\end{tabular}

andependent t-test was applied. * $\mathrm{p}<0.05$.

Table II: Anthropometric measurements according to age group $(n=131)$

\begin{tabular}{|c|c|c|c|c|c|}
\hline Characteristic & $<60$ years $(n=45)$ & $\begin{array}{c}\text { Mean (SD) } \\
\geq 60 \text { years }(n=86)\end{array}$ & Total $(n=131)$ & Range & p-value ${ }^{a}$ \\
\hline Weight (kg) & $76.52(1.13)$ & 70.56 (16.94) & $72.61(15.67)$ & $34.4-130.0$ & $0.038^{*}$ \\
\hline Height (cm) & $155.86(6.28)$ & $153.11(7.59)$ & $154.06(7.26)$ & 139.3-173.0 & $0.020 *$ \\
\hline BMI (kg/m2) & $31.22(4.17)$ & 30.02 (6.57) & $30.51(5.88)$ & 17.7-53.39 & $0.133^{*}$ \\
\hline WC (cm) & $100.36(10.94)$ & $98.12(11.44)$ & $98.89(11.28)$ & 63.6-122.7 & 0.283 \\
\hline $\mathrm{BF}(\%)$ & $44.80(5.05)$ & $39.96(8.16)$ & $41.62(7.58)$ & $23.3-58.4$ & $0.001 *$ \\
\hline
\end{tabular}

andependent t-test was applied. ${ }^{*} p<0.05$.

Table III: Dietary intake according to gender $(n=131)$

\begin{tabular}{|c|c|c|c|c|}
\hline Variables & Total $(n=131)$ & $\begin{array}{c}\text { Mean (SD) } \\
\text { Male }(n=25)\end{array}$ & Female $(n=106)$ & p-value ${ }^{a}$ \\
\hline Energy (kcal) & $1693.07(610.41)$ & $1925.24(552.67)$ & $1638.32(612.89)$ & $0.034 *$ \\
\hline Carbohydrate (g) & $227.11(57.57)$ & $280.65(62.14)$ & $214.49(48.75)$ & $0.001^{*}$ \\
\hline Protein $(g)$ & $67.52(20.28)$ & 78.89 (29.42) & $64.83(16.54)$ & $0.029 *$ \\
\hline Fat $(g)$ & $53.84(21.31)$ & $61.75(31.06)$ & 51.97 (17.99) & 0.141 \\
\hline Dietary Fibre (g) & $2.80(1.78)$ & $2.41(1.50)$ & $2.92(1.83)$ & 0.194 \\
\hline Sodium (mg) & $1975.99(968.58)$ & $1923.75(832.36)$ & $1988.31(1001.17)$ & 0.766 \\
\hline Potassium (mg) & $1448.92(414.01)$ & $1549.68(552.05)$ & $1425.16(373.59)$ & 0.293 \\
\hline Calcium (mg) & $432.07(219.55)$ & $425.74(267.59)$ & $433.57(208.08)$ & 0.873 \\
\hline Cholesterol (mg) & $159.50(102.57)$ & $193.90(167.63)$ & 151.39 (79.09) & 0.227 \\
\hline Vitamin A (RE) & 739.43 (437.78) & 737.29 (565.89) & 739.93 (405.07) & 0.979 \\
\hline Vitamin $D(\mu \mathrm{g})$ & $8.22(92.17)$ & $0.04(0.21)$ & $10.15(102.46)$ & 0.624 \\
\hline Vitamin E (mg) & $4.15(1.34)$ & $4.09(1.41)$ & $4.16(1.32)$ & 0.799 \\
\hline Vitamin $\mathrm{K}(\mu \mathrm{g})$ & $18.44(19.15)$ & $14.98(16.77)$ & $19.25(19.65)$ & 0.318 \\
\hline Vitamin C (mg) & $62.37(45.55)$ & $46.13(34.49)$ & $66.20(47.11)$ & $0.047 *$ \\
\hline
\end{tabular}

andependent t-test was applied. ${ }^{*} \mathrm{p}<0.05$.

Table IV: Dietary intake according to age group $(n=131)$

\begin{tabular}{|c|c|c|c|c|}
\hline Variables & Total $(n=131)$ & $\begin{array}{c}\text { Mean }(\mathrm{SD}) \\
<60 \text { years }(n=45)\end{array}$ & $\geq 60$ years $(n=86)$ & p-value ${ }^{a}$ \\
\hline Energy (kcal) & $1693.07(610.41)$ & $1762.36(434.58)$ & $1656.82(684.27)$ & 0.349 \\
\hline Carbohydrate (g) & $227.11(57.57)$ & $229.97(52.73)$ & $225.62(60.19)$ & 0.683 \\
\hline Protein (g) & $67.52(20.28)$ & $71.78(23.56)$ & $65.28(18.09)$ & 0.082 \\
\hline Fat (g) & $53.84(21.31)$ & $61.37(20.45)$ & $49.90(27.80)$ & $0.003^{*}$ \\
\hline Dietary Fibre (g) & $2.80(1.78)$ & $2.77(1.65)$ & $2.85(1.85)$ & 0.804 \\
\hline Sodium (mg) & $1975.99(968.58)$ & $2021.34(895.04)$ & $1952.26(1009.19)$ & 0.700 \\
\hline Potassium (mg) & $1448.92(414.01)$ & $1478.15(409.17)$ & $1433.63(418.09)$ & 0.561 \\
\hline Calcium (mg) & 432.07 (219.55) & $457.31(226.71)$ & $418.87(215.87)$ & 0.343 \\
\hline Cholesterol (mg) & $159.50(102.57)$ & $181.66(11.93)$ & $147.91(94.74)$ & 0.074 \\
\hline Vitamin A (RE) & 739.43 (437.78) & $955.42(492.45)$ & $626.41(360.50)$ & $0.001 *$ \\
\hline Vitamin D $(\mu \mathrm{g})$ & $8.22(92.17)$ & $23.64(157.25)$ & $0.15(0.82)$ & 0.167 \\
\hline Vitamin E (mg) & $4.15(1.34)$ & $4.49(1.49)$ & $3.97(1.22)$ & $0.032^{*}$ \\
\hline Vitamin $\mathrm{K}(\mu \mathrm{g})$ & $18.44919 .15)$ & $19.42(20.07)$ & $19.92(18.75)$ & 0.673 \\
\hline Vitamin C (mg) & $62.37(45.55)$ & $66.37(54.96)$ & $60.27(36.48)$ & 0.468 \\
\hline
\end{tabular}

Independent t-test was applied. * $\mathrm{p}<0.05$. 
Table V: HRQOL according to gender by using OAKHQOL questionnaire $(n=131)$

\begin{tabular}{|lcccc|}
\hline Mean (SD) & Motal $(\mathbf{n}=\mathbf{1 3 1})$ & $\begin{array}{c}\text { Mean (SD) } \\
\text { Male }(\mathbf{n = 2 5})\end{array}$ & Female $(\mathbf{n = 1 0 6 )}$ & p-value $^{\mathrm{a}}$ \\
\hline Physical & $41.6(22.81)$ & $38.69(22.81)$ & $41.62(22.89)$ & 0.566 \\
Mental & $21.15(20.92)$ & $15.95(12.71)$ & $22.37(21.86)$ & 0.168 \\
Pain & $38.78(22.05)$ & $32.00(20.26)$ & $40.33(22.25)$ & 0.097 \\
SF & $41.25(27.16)$ & $43.33(30.99)$ & $40.75(26.32)$ & 0.671 \\
SS & $21.32(18.70)$ & $19.93(21.70)$ & $21.89(17.99)$ & 0.480 \\
\hline
\end{tabular}

andependent t-test; SF-Social Functioning; SS-Social Support

Table VI: HRQOL according to age group by using OAKHQOL questionnaire $(n=131)$

\begin{tabular}{|c|c|c|c|c|}
\hline Domain & Total $(=131)$ & $\begin{array}{c}\text { Mean }(S D) \\
<60 \text { years }(n=45)\end{array}$ & $\geq 60$ years $(n=106)$ & p-value ${ }^{a}$ \\
\hline Physical & $41.06(22.81)$ & $36.84(16.23)$ & $43.27(25.40)$ & 0.081 \\
\hline Mental & $21.15(20.92)$ & $26.69(25.68)$ & $18.24(17.41)$ & $0.028^{*}$ \\
\hline Pain & $38.78(22.05)$ & $39.67(23.29)$ & $38.31(21.49)$ & 0.740 \\
\hline SF & $41.25(27.16)$ & $34.67(27.36)$ & $44.68(26.57)$ & $0.044^{*}$ \\
\hline SS & $21.32(18.70)$ & $21.11(16.920)$ & $21.43(16.92)$ & 0.926 \\
\hline
\end{tabular}

Independent t-test; SF-Social Functioning; SS-Social Support

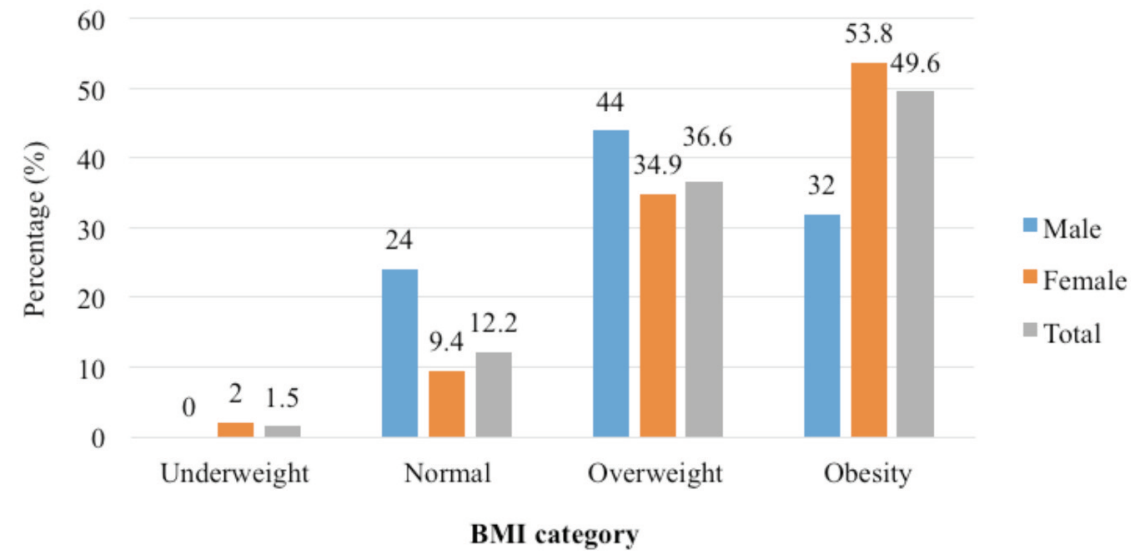

Fig. 1: Percentage of BMI classification according to gender $(n=131)$.

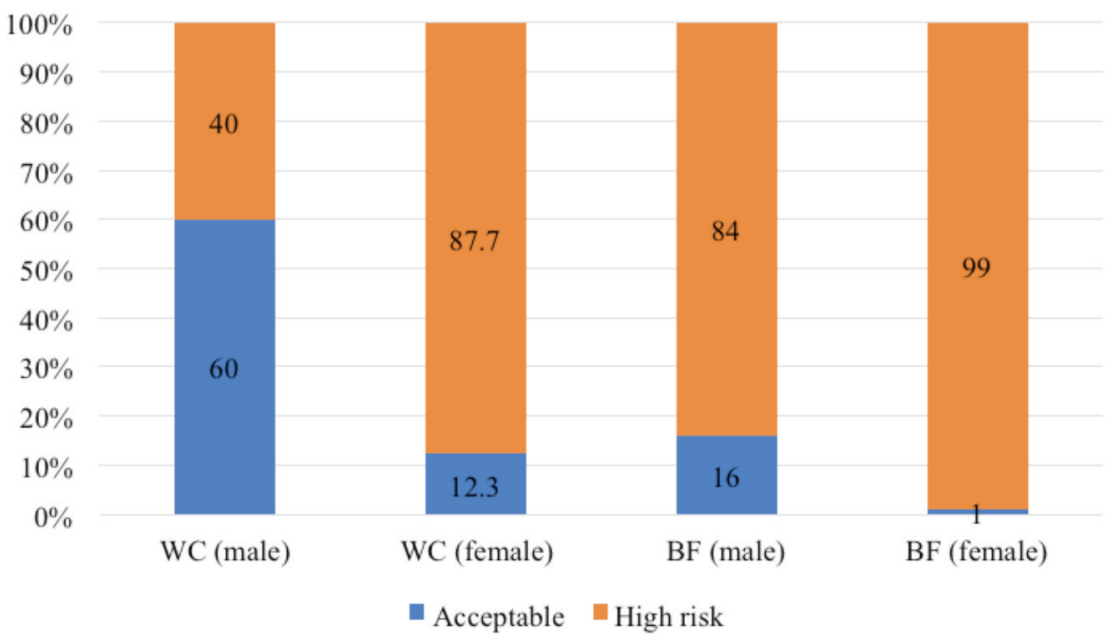

Fig. 2: Percentage of WC and BF compared to cut-off value for male $(n=25)$ and female $(n=106)$. 


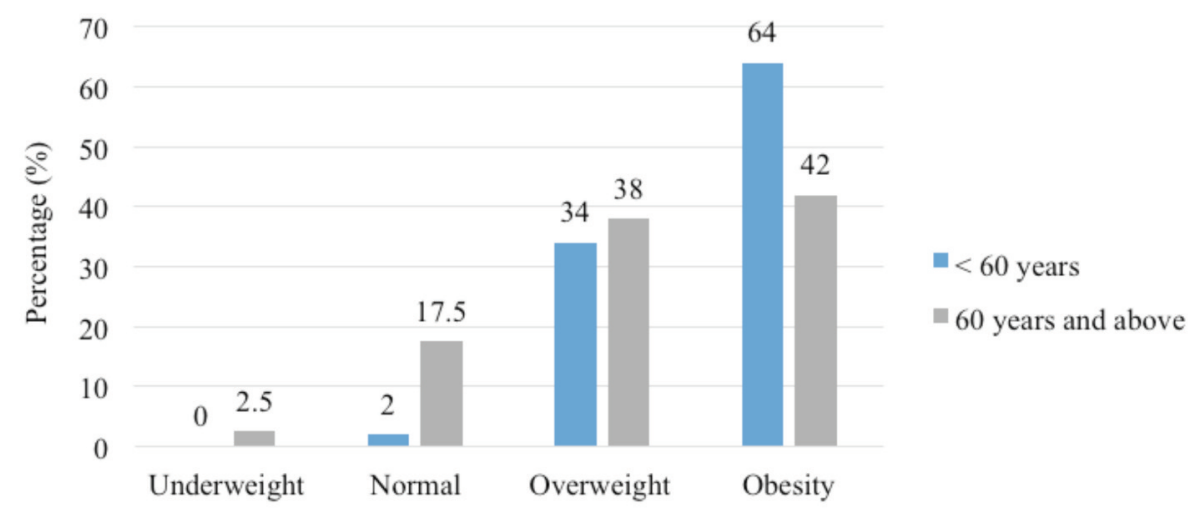

BMI category

Fig. 3: Percentage of BMI classification according to age group $(n=131)$.

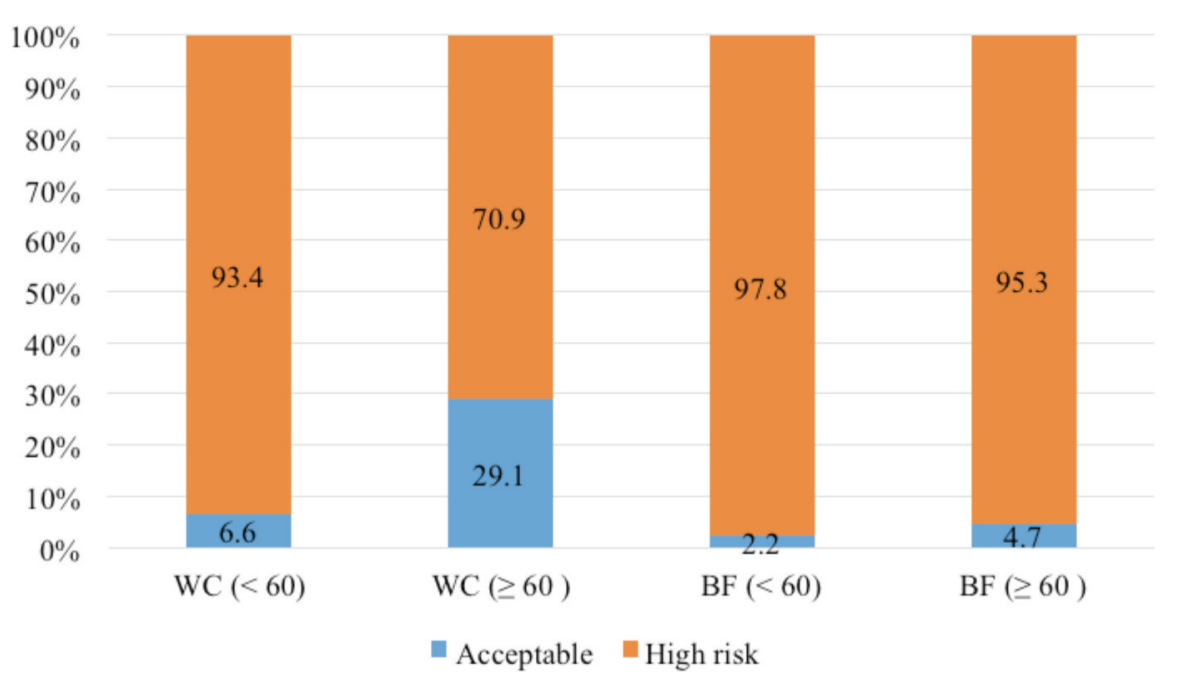

Fig. 4: Percentage of $W C$ and BF compared to cut-off value for patients $<60$ years old $(n=45)$ and patient aged $\geq 60$ years $(n=86)$.

In terms of age breakdown, patients who were $<60$ years had significantly higher weight $(\mathrm{p}=0.038)$, height $(\mathrm{p}=0.030)$, and BF ( $p=0.001)$ compared to those $\geq 60$ years old (Table II). For the BMI classification, patients who were $<60$ years old had a lower percentage of overweight (34.0\%) but higher percentage of obesity (64.0\%) compared to those aged $\geq 60$ years $(38.0 \%, 42.0 \%)$ (Fig. 3). Meanwhile, patients who were $<60$ years had a higher risk for WC (93.4\%) and BF $(97.8 \%)$ compared to those aged $\geq 60$ years $(70.9 \%, 95.3 \%)$ (Fig. 4).

Table III and IV show the total energy and nutrient intakes (i.e. macronutrients and micronutrients) of the knee and/or hip OA patients according to gender and age groups, respectively. Overall, the patients consumed $1693 \mathrm{kcal} /$ day comprising of $227 \mathrm{~g}$ of carbohydrate, $67 \mathrm{~g}$ of protein, and $53 \mathrm{~g}$ of fat.
Considering Table III, the male respondents consumed significantly more energy $(p=0.034)$, carbohydrate $(p=$ $0.001)$, and protein $(\mathrm{p}=0.029)$ but less vitamin $\mathrm{C}(\mathrm{p}=0.047)$ than the females. However, no significant mean difference was seen in terms of fat, dietary fibre, sodium, potassium, calcium, cholesterol, and vitamin $\mathrm{A}, \mathrm{D}$, and $\mathrm{K}$ intakes between the male and female respondents.

Besides, a significant mean difference was observed regarding fat $(\mathrm{p}=0.003)$, vitamin $\mathrm{A}(\mathrm{p}=0.001)$, and vitamin $E$ intakes $(p=0.032)$ between patients aged $<60$ years and $\geq 60$ years (Table IV). Patients aged $<60$ years consumed more fat, vitamin $\mathrm{A}$, and vitamin $\mathrm{E}$ compared to their counterparts (aged $\geq 60$ years). In contrast, no significant mean differences were observed for the remaining nutrient intakes between the age groups. 
The HRQOL score according to the domains is shown in (Table V) (gender comparison) and VI (age group comparison) accordingly. The scores were standardised on a scale from 0 (best possible QOL) to 100 (worst possible QOL). Overall, SF domain recorded the highest value of 41.25 (27.16), while mental domain recorded the lowest score of 21.15 (20.92). According to gender as shown in (Table V), the males reported the highest score in social functioning at 43.33 (30.99) while the females obtained the highest score in the physical domain 41.62 (22.89). However, no significant difference in the HRQOL domains was observed in both genders.

In terms of age, the patients aged $<60$ years were more affected in the pain domain with 39.67 (23.29), while those aged 60 years and above were more affected in the physical domain 43.27 (25.40). Next, a significantly higher score in the mental domain was observed in the patients aged $<60$ years compared to their counterparts $(p=0.028)$, while those aged $\geq 60$ years scored higher in the SF domain $(p=0.044)$ (Table VI)

\section{DISCUSSION}

The present study found that the mean age of the patients was 61.81 (9.28) years, which was relatively younger compared to a previous local study ${ }^{16}$ and other international studies $^{11,17}$. A majority of the patients involved in this study were 60 years old or older, which was similar to a previous study $^{17}$. Therefore, OA is strongly associated with ageing, whereby a scoping review has reported that subjects aged 50 years and above are more vulnerable to OA compared to those younger than 50 years old $^{18}$. These findings are supported by a previous research report that the increasing OA prevalence with age may be caused by biological changes. They render a joint less capable to cope with adversities, such as cartilage thinning, weak muscle strength, poor proprioception, and oxidative damage ${ }^{19}$.

Besides, this current study found that a majority of the patients involved were females $(80.9 \%)$, which was in agreement with previous studies ${ }^{11,20-22}$. Females are usually associated with a higher prevalence and more severe case of OA due to menopausal effect. The significant increase of OA in female around the time of menopause has led to multiple investigations of the hormonal effect on its pathophysiology. However, the results of the effect of oestrogen therapy have been conflicting as oestrogen usage is linked to a healthy lifestyle and osteoporosis, which can lower the risk of OA. Besides, females may have a reduced volume of knee cartilage than the males but it is not clear if this can contribute to an accelerated cartilage loss ${ }^{20}$.

Furthermore, the present study found that most of the patients involved were unemployed (79.4\%) consisting of housewives and pensioners, as well as having a low household income $(90.8 \%)$. These findings are in agreement with a previous study conducted in India ${ }^{23}$, which has reported that the socioeconomic status can be measured in terms of the income, wealth, poverty, education, occupation, and area-level measures ${ }^{24}$. Similarly, a study by Callahan et al $(2011)^{25}$ has found that both education and socioeconomic status are independently associated with knee OA, whereas Robbel et al (2014) ${ }^{23}$ has stated that low socioeconomic status comprising of low educational attainment, occupational status, and income may pose an additional risk factor for the disease development.

Moreover, the present study found that the mean disease duration was 4.27 (4.68) years. This is comparable to a local study ${ }^{16}$ and other international studies ${ }^{26}$ accordingly. Besides, it was found that a majority of the patients had been diagnosed with knee and/or hip OA within one to five years (55.8\%), which was in agreement with Harsha Kumar et al $(2015)^{22}$. Meanwhile, most of the patients in this study had two comorbidities (26.7\%), which paralleled previous studies $^{16,17,22}$. Additionally, a majority of the patients had hypertension (62.6\%), followed by hyperlipidaemia (58.0\%) and diabetes mellitus (36.6\%), which reflected the prevalence of these three diseases among the adults in Malaysia $^{27-29}$. A meta-analysis study had shown a significant relationship between hypertension and knee OA (i.e. radiographic and symptomatic) ${ }^{30}$.

The present study found that a majority of the patients had a sedentary lifestyle $(84.7 \%)$ and inadequate intake of vegetable $(87.0 \%)$, fruit $(87.8 \%)$, and milk (64.1\%). Most reported that they had limited movements or were sedentary due to knee pain, which was noted in a previous study that correlated a longer sedentary behaviour with chronic knee pain. A sedentary behaviour exceeding $10 \mathrm{hrs} /$ day has been noted to be significantly associated with chronic knee pain. However, participants with high levels of physical activity were less likely to suffer from chronic knee pain, while women with over 10 daily hrs of sedentary behaviour and high level of physical activity were more likely to have chronic knee pain. The researcher has also reported a significant association between chronic knee pain and obese $\left(\geq 30.0 \mathrm{~kg} / \mathrm{m}^{2}\right)$ individuals $\mathrm{s}^{31}$.

Accordingly, the present study showed a low intake of vegetables and fruits among the patients, which was in agreement with a few previous studies. A majority of the patients also reported the inadequate intake in their daily lives was due to food availability and chewing difficulties, especially in the elderly group. A recent cross-sectional study from the Korean National Health and Nutrition Examination Survey has revealed the higher intake of fruits and vegetables to be significantly associated with a lower prevalence of knee pain in older adults with knee $\mathrm{OA}^{32}$. Meanwhile, another study from India has reported that low fruit consumption is associated with a high prevalence of 
knee $\mathrm{OA}^{33}$. Additionally, a researcher has shown that dietary fruits, especially berries, are a rich source of several phytochemicals and nutrients, which may explain much of their physiological effects as antioxidants and antiinflammatory agents ${ }^{34}$.

The present study also found that low milk intake among the patients was due to the high cost of milk purchase, whereby the low intake could be supported by a few previous studies. A previous study conducted among the Dutch population has indicated that a higher intake of full-fat dairy and Dutch cheese products as opposed to milk is associated with a lower presence of knee $\mathrm{OA}^{35}$. Besides, a prospective study by $\mathrm{Lu}$ and colleagues has included 2,148 men and women participants in the Osteoarthritis Initiative (OAI) in which a baseline dietary assessment is done, enquiring the usual frequency of milk, yoghurt, and cheese intake over the past 12 months. Then, OA progression over 48 months of followup was evaluated as a change in quantitative joint space width (JSW) between the medial femur and tibia of the knee based on plain radiographs. As a result, the main finding noted that a greater milk consumption was associated with reduced joint space narrowing in women but not in men. Therefore, the researchers concluded that women who were "milk drinkers" would experience 4-year decrease in JSW, specifically from 0.09 to $0.12 \mathrm{~mm}$, than the non-milk drinkers. However, a more frequent cheese intake is associated with a greater joint space narrowing in women alone, while no associations are seen with yoghurt intake ${ }^{36}$.

The present study found that the mean BMI was 29.11 (5.44) $\mathrm{kg} / \mathrm{m}^{2}$, which was in agreement with a local study ${ }^{16}$ but a bit lower compared to Rogers and Wilder ${ }^{37}$. A majority of the patients was categorised as obese $(49.6 \%)$. A previous study has reported that high $\mathrm{BMI}$ is a risk factor of knee $\mathrm{OA}^{38}$, whereas obesity (i.e. defined as BMI $\geq 30 \mathrm{~kg} / \mathrm{m}^{2}$ ) and abdominal obesity are strongly related to radiographic knee OA. Moreover, it has been noted that every $5 \mathrm{~kg}$ of body weight gained increases the risk of knee OA by $36 \%{ }^{39}$. Therefore, healthcare professionals should take account of a possible weight reduction in planning the treatment of knee OA whenever a patient is significantly overweight.

Besides, the WC variable in the present study revealed that a majority of the male respondents was categorised as acceptable $(60.0 \%)$, while most of the females were categorised as the high-risk group $(87.7 \%)$. This is similar with a previous study ${ }^{40}$, which has also reported central obesity as a key factor in metabolic syndrome (MetS). The relationship between $\mathrm{OA}$ and MetS or its components has been evaluated accordingly by Engstrom et al (2009) $)^{41}$, whereby it is found that MetS is associated with an increased incidence of knee $\mathrm{OA}$ in a Western population after adjustments are made for the age, sex, and social factors ${ }^{41}$.
Overall, the present study found that the most affected HRQOL parameter among the patients was social functioning, which was similar to a previous study ${ }^{42}$. In contrast, the least affected HRQOL parameter was mental health domain, which differed from Ouedraogo et al (2014) ${ }^{42}$ as the study reported the domain to be most affected by using the SF-36 questionnaire. The social functioning domain was the most affected parameter in the present study due to ageing and disease severity among the patients, who reported their social functioning to be less functional compared to pre-diagnosis of knee and/or hip OA. Therefore, they preferred to isolate themselves from other people due to the disease severity. Moreover, the present findings are consistent with a previous study that had reported poorer social functioning to be related to more depressive symptoms, but both poorer social and physical functioning predicted worse perceived in health ${ }^{43}$.

In the present study, the mental health domain was the least affected parameter in the HRQOL, which was similar to a local study ${ }^{16}$ despite the use of a different instrument, namely the SF-36 Questionnaire. The mental health domain was found to be the least affected due to better coping mechanisms and adaptation to the chronic disease. A previous study has found patients with knee OA have various coping mechanisms and result in less pain and better mood compared to those with rheumatoid arthritis ${ }^{44}$. In contrast, the previous studies by Mahmoud et al (2019) and Ouedraogo et al $(2014)^{26,42}$ have reported that the pain domain is the least affected parameter in HRQOL.

The present study found that the male respondents had higher body weight and height but lower BF compared to the females. The present findings on BF were consistent with those of a previous study by Blaak $(2001)^{45}$. Besides, for BMI categorisation, the males had a lower percentage $(32.0 \%)$ of obesity status than the females $(53.8 \%)$, which was parallel to a previous study by Kim et al $(2010)^{46}$. Meanwhile, male WC showed a lower $(40.0 \%)$ percentage of high risk compared to the female WC $(87.7 \%)^{47}$. Similarly, dietary intake showed significant differences for energy, carbohydrate, protein, and vitamin $\mathrm{C}$ between male and female in this study. Since a limited number of studies are done on dietary intake, a comparison is not possible. For HRQOL, no significant difference was seen for all domains between male and female, regardless. The present study concluded with the results that females had a higher percentage of body fat, obesity status, and high risk of WC.

Similarly, the present study found that patients aged $<60$ years had higher weight, height, and BF compared to those aged $\geq 60$ years. This finding is inconsistent with a previous study; ${ }^{48}$ although the subject of the study is of a healthy population, the researcher has reported that a decrease in fatfree mass and increase in BF percentage are observed with ageing. In contrast, the present findings on WC showed 
inconsistencies with the previous study, which reported that abdominal obesity increases with ageing ${ }^{49}$. For dietary intake, patients aged $<60$ years consumed more fat and vitamin $\mathrm{A}$ and $\mathrm{E}$ compared to those aged $\geq 60$ years. This may be attributed to fat malabsorption commonly present among those aged $\geq 60$ years $^{50}$.

For HRQOL, the present study found that patients aged $<60$ years had a higher mental score and a lower social functioning score compared to those aged $\geq 60$ years. This indicated that patients aged $\geq 60$ years had better mental health but poorer social functioning, which was similar to ${ }^{16}$. Therefore, it could be concluded that the high prevalence of knee and/or hip OA patients in the present study was due to the high percentage of $\mathrm{BF}$, obesity status, and high risk for WC among patients aged $<60$ years. Therefore, some of the secondary prevention methods include dietary intervention and exercise, which are the basic management for individuals who are overweight or obese ${ }^{51}$.

This study, however, has several methodological limitations. The present study was conducted in the rehabilitation centre in Kuala Nerus, Terengganu only due to financial constraints, thus limiting generalisation of the results to other communities, which comprised of other ethnicities such as Chinese and Indians, whereby dietary intake are likely to be different. This is because Kuala Nerus had $97.0 \%$ of the Malay population, and the rest are Chinese, Indians, and other ethnicities, according to the Department of Statistics Malaysia $(2010)^{52}$. The findings in the dietary intake of knee and/or hip OA are subject to limitations. The assessment of dietary intake in the present study using the 24-hr dietary recall maybe overreporting or underreporting of total calorie and nutrient intake. More independents variables should be considered such as biochemical data, specific physical activity data and specific rehabilitation program should be considered to get more accurate results.

\section{CONCLUSION}

Most of the OA patients in this study were inactive and had an imbalance of dietary intake, resulting in a majority of them being overweight or obese and had a high percentage of BF and adiposity fat, which was measured as the WC. In terms of gender breakdown, the males had significantly greater weight and height but lower BF compared to their female counterparts, as well as a significantly higher energy, carbohydrate, and protein intake. However, no significant differences were found in the HRQOL between genders. Meanwhile, according to the age group, patients aged $<60$ years had significantly greater weight, height, and $\mathrm{BF}$ than those aged $\geq 60$ years. Similarly, the fat and vitamin A and E intakes were significantly lower in patients aged $\geq 60$ years. Next, a significantly higher score in the mental domain was observed in the patients aged $<60$ years, while those aged $\geq$ 60 years scored higher in the SF domain. Hence, this study is an important baseline reference for proper knee and/or hip OA management and prevention. Accordingly, healthcare professionals should take into account regarding possible weight reduction and a physically active lifestyle in order to prevent OA.

\section{ACKNOWLEDGEMENT}

The authors would like to express their gratitude and appreciation to all participating patients and health care providers for their cooperation, support and contribution to this study.

\section{CONFLICT OF INTEREST}

The authors declare no potential conflict of interest. 


\section{REFERENCES}

1. Castaneda S, Roman-blas JA, Largo R, Herrero-beaumont G. Subchondral bone as a key target for osteoarthritis treatment. Biochem Pharmacol. 2012; 83(3): 315-23. doi: 10.1016/j.bcp.2011.09.018

2. March L, Smith EUR, Hoy DG, Cross MJ, Sanchez-riera L, Blyth F, et al. Burden of disability due to musculoskeletal (MSK) disorders. Best Pract Res Clin Rheumatol. 2014; 28(3): 353-66. doi: 10.1016/j.berh.2014.08.002

3. Cross M, Smith E, Hoy D, Nolte S, Ackerman I, Fransen M, et al. The global burden of hip and knee osteoarthritis : estimates from the Global Burden of Disease 2010 study. Ann Rheum Dis. 2014; 73(7): 1323-30. doi: 10.1136/annrheumdis-2013-204763

4. Murray CJL, Vos T, Lozano R, Naghavi M, Flaxman AD, Michaud C, et al. Disability-adjusted life years (DALYs) for 291 diseases and injuries in 21 regions , 1990 - 2010 : a systematic analysis for the Global Burden of Disease Study 2010. Lancet. 2014; 380(9859): 2197-223. doi: 10.1016/S0140-6736(12)61689-4.

5. Palazzo C, Nguyen C, Lefevre-Colau MM, Rannou F, Poiraudeau S. Risk factors and burden of osteoarthritis. Ann Phys Rehabil Med. 2016; 59(3): 134-138. doi: 10.1016/j.rehab.2016.01.006

6. March L, Cross M, Lo C, Arden NK, Hawker G, Gates L, et al. Osteoarthritis: A serious disease: Submitted to the U.S. Food and Drug Administration. 2016. 103 p.

7. Cohen J. Statistical Power Analysis for the Behavioral Sciences. 2nd ed. New York: Routledge Academic; 1988. 567 p.

8. Institute for Public Health. National Health and Morbidity Survey 2015 (NHMS 2015). Vol. II: Non-communicable diseases, risk factors \& other health problems. Kuala Lumpur: Ministry of Health; 2015. 291 p.

9. Reisa JG, Neves MMGTM, Petrella M, Oliveira RDR de, Cristina D, Abreu C de. Evaluation of postural control and quality of life in elderly women with knee osteoarthritis. Rev Bras Reumatol. 2014; 54(3): 208-12. doi: 10.1016/j.rbr.2013.11.002

10. Woolf AD, Pfleger B. Burden of major musculoskeletal conditions. Bull World Health Organ. 2003; 81(9): 646-56.

11. Gomes-neto M, Delano A, Dayanne I, Junqueira A, Oliveira D, Brasileiro A, et al. Comparative study of functional capacity and quality of life among obese and non-obese elderly people with knee osteoarthritis. Rev Bras Ortop. 2015; 56(2): 126-30. doi: 10.1016/j.rbre.2015.08.014

12. Altman R, Asch E, Bloch D, Bole G, Borenstein D, Brandt K, et al. Development of criteria for the classification and reporting of osteoarthritis. Classification of osteoarthritis of the knee. Diagnostic and Therapeutic Criteria Committee of the American Rheumatism Association. Arthritis Rheum. 1986; 29(8): 1039-49. doi: 10.1002/art.1780290816

13. Abdul Kadir A, Mohd Arif MF, Ishak A, Hassan II, Mohd Noor N. Adaptation and validation of the Malay version of the Osteoarthritis Knee and Hip Quality of Life (OAKHQOL) questionnaire among Knee Osteoarthritis Patients. Biomed Res Int. 2018; 2018: 4329751. doi: 10.1155/2018/4329751

14. Ngoh HJ, Sakinah H, Harsa Amylia MS. Development of demi-span equations for predicting height among the Malaysian elderly. Malays J Nutr. 2012;18(2):149-59.

15. World Health Organisation (WHO). Waist circumference and waist-hip ratio. Report of a WHO expert consultation. Geneva, 811 December 2008. 2011. https://www.who.int/publications/i/item/9789241501491 (accessed on 28 January 2020)

16. Zakaria ZF, Bakar AA, Hasmoni HM, Rani FA, Kadir SA. Health-related quality of life in patients with knee osteoarthritis attending two primary care clinics in Malaysia: A cross-sectional study. Asia Pac Fam Med. 2009; 8(1): 10. doi: 10.1186/1447056X-8-10

17. Norimatsu T, Osaki M, Tomita M, Ye Z, Abe Y, Honda S, et al. Factors predicting health-related quality of life in knee osteoarthritis Aamong community-dwelling women in Japan: The Hizen-Oshima study. Orthopedics. 2011; 34(9): e535-40. doi: 10.3928/01477447-20110714-04.

18. Zamri NAA, Harith S, Mohd Yusoff NA, Mat Hassan N, Ong YQ. Prevalence, risk factors and primary prevention of osteoarthritis in Asia: A scoping review. Elder Heal J. 2019; 5(1): 19-31. doi: 10.18502/ehj.v5i1.1196

19. Zhang JF, Song L hua, Wei J ni, Zhang A lian, Dong H yuan, Wen H yan, et al. Prevalence of and risk factors for the occurrence of symptomatic osteoarthritis in rural regions of Shanxi Province, China. Int J Rheum Dis. 2016; 19(8): 781-9. doi: 10.1111/1756$185 X .12470$ 
20. Johnson VL, Hunter DJ. The epidemiology of osteoarthritis. Best Pract Res Clin Rheumatol. 2014; 28(1): 5-15. doi: 10.1016/j.berh.2014.01.004

21. Kawano MM, Araújo ILA, Castro MC, Matos MA. Assessment of quality of life in patients with knee osteoarthritis. Acta Ortop Bras. 2015; 23(6): 307-10. doi: 10.1590/1413-785220152306150596

22. Harsha Kumar HN, Nagaraj K, Luthra K, Gupta P, Sapar P, Gupta S, et al. Health-related quality of life among osteoarthritis patients attending primary care clinics of Mangalore city. Int J Med Public Heal. 2015; 5(1): 55-8. doi: 10.4103/22308598.151260

23. Robbel L, Limaye PD, Limaye PV, Fortwengel G. The association between socioeconomic status and the incidence of osteoarthritis in Mumbai and its rural periphery. Int J Pharm Sci Invent. 2014; 3(4): 27-36.

24. Braveman PA, Cubbin C, Egerter S, Chideya S, Marchi KS, Metzler M, et al. Socioeconomic status in health research: One size does not fit all. J Am Med Assoc. 2005; 294(22): 2879-88. doi: 10.1001/jama.294.22.2879

25. Callahan LF, Cleveland RJ, Shreffler J, Schwartz TA, Schoster B, Randolph R, et al. Associations of educational attainment, occupation and community poverty with knee osteoarthritis in the Johnston County (North Carolina) osteoarthritis project. Arthritis Res Ther. 2011; 13(5): R169. doi: 10.1186/ar3492

26. Mahmoud GA, Moghazy A, Fathy S, Niazy MH. Osteoarthritis knee hip quality of life questionnaire assessment in Egyptian primary knee osteoarthritis patients: Relation to clinical and radiographic parameters. Egypt Rheumatol. 2019; 41(1): 65-9. doi: 10.1016/j.ejr.2018.05.001

27. Mat Rifin H, Robert Lourdes TG, Ab Majid NL, Abd Hamid HA, Rodzlan Hasani WSMYL, Saminathan TA, et al. Hypercholesterolemia prevalence, awareness, treatment and control among adults in Malaysia: The 2015 National Health and Morbidity Survey, Malaysia. Glob J Heal Sci. 2018; 10(7): 11-23. doi: 10.5539/gjhs.v10n7p11

28. Ab Majid N, Omar M, Khoo Y, Mahadir Naidu B, Ling Miaw Yn J, Rodzlan Hasani W, et al. Prevalence, awareness , treatment and control of hypertension in the malaysian population: Findings from the National Health and Morbidity Survey $2006-2015$. J Hum Hypertens. 2018; 32(8-9): 617-24. doi: 10.1038/s41371-018-0082-x

29. Wan Nazaimoon W, Md Isa S, Wan Mohamad W, Khir A, Kamaruddin N, Kamarul I, et al. Prevalence of diabetes in Malaysia and usefulness of HbA 1c as a diagnostic criterion. Diabet Med. 2013; 30(7): 825-8. doi: 10.1111/dme.12161

30. Zhang Y, Wang J, Liu X. Association between hypertension and risk of knee osteoarthritis. Medicine (Baltimore). 2017; 96(32): e7584. doi: 10.1097/MD.0000000000007584

31. Lee SH, Son C, Yeo S, Ha IH. Cross-sectional analysis of self-reported sedentary behaviors and chronic knee pain among South Korean adults over 50 years of age in KNHANES 2013-2015. BMC Public Health. 2019; 19(1): 1375. doi: 10.1186/s12889-0197653-9

32. Han HS, Chang CB, Lee DC, Lee JY. Relationship between total fruit and vegetable intake and self-reported knee pain in older adults. J Nutr Heal Aging. 2017; 21(7): 750-8. doi: 10.1007/s12603-016-0842-7

33. Sanghi D, Mishra A, Sharma AC, Raj S, Mishra R, Kumari R, et al. Elucidation of dietary risk factors in osteoarthritis knee-A case-control study. J Am Coll Nutr. 2014; 34(1): 15-20. doi: 10.1080/07315724.2013.875439

34. Basu A, Schell J, Scofield RH. Dietary fruits and arthritis. Food Funct. 2018; 9(1): 70-7. doi: 10.1039/c7fo01435j

35. Denissen KFM, Boonen A, Nielen JTH, Feitsma AL, Heuvel EGHM Van Den, Emans PJ, et al. Consumption of dairy products in relation to the presence of clinical knee osteoarthritis: The Maastricht Study. Eur J Nutr. 2019; 58(7): 2693-704. doi: 10.1007/s00394-018-1818-7

36. Lu B, Driban JB, Duryea J, McAlindon T, Lapane KL, Eaton CB. Milk consumption and progression of medial tibiofemoral knee osteoarthritis: data from the Osteoarthritis Initiative. Arthritis Care Res (Hoboken). 2014; 66(6): 802-9. doi: 10.1002/acr.22297

37. Rogers MW, Wilder FV. The association of BMI and knee pain among persons with radiographic knee osteoarthritis: A crosssectional study. BMC Musculoskelet Disord. 2008; 9: 163. doi: 10.1186/1471-2474-9-163

38. Zhang J, Song L, Liu G, Zhang A, Dong H, Liu Z, et al. Risk factors for and prevalence of knee osteoarthritis in the rural areas of Shanxi Province, North China: a COPCORD study. Rheumatol Int. 2013; 33(11): 2783-8. doi: 10.1007/s00296-013-2809-x 
39. Vasilic-Brasnjevic S, Marinkovic J, Vlajinac H, Vasiljevic N, Jakovljevic B, Nikic M, et al. Association of body mass index and waist circumference with severity of knee osteoarthritis. Acta Reumatol Port. 2016; 41(3): 226-31.

40. Han CD, Yang IH, Lee WS, Park YJ, Park KK. Correlation between metabolic syndrome and knee osteoarthritis: Data from the Korean National Health and Nutrition Examination Survey (KNHANES). BMC Public Health. 2013; 13: 603. doi: 10.1186/14712458-13-603

41. Engstrom G, Gerhardsson de Verdier M, Rollof J, Nilsson PM, Lohmander LS. C-reactive protein, metabolic syndrome and incidence of severe hip and knee osteoarthritis. A population-based cohort study. Osteoarthr Cartil. 2009; 17(2): 168-73. doi: 10.1016/j.joca.2008.07.003

42. Ouedraogo DD, Zabsonre JT, Kenagnon ADS, Kabore F, Compaore C, Drabo YJ, et al. Quality of life of patients with knee osteoarthritis with questionnaire OAKHQOL (OsteoArthritis of Knee Hip Quality of Life) in rheumatology consultation in Burkina Faso (West Africa). Open J Rheumatol Autoimmune Dis. 2014; 4(4): 219-25. doi: 10.4236/ojra.2014.44030

43. Bookwala J, Harralson TL, Parmelee PA. Effects of pain on functioning and well-being in older adults with osteoarthritis of the knee. Psychol Aging. 2003; 18(4): 844-50. doi: 10.1037/0882-7974.18.4.844

44. Kempen GIJM, Ormel J, Brilman EI, Relyveld J. Adaptive responses among Dutch elderly: The impact of eight chronic medical conditions on health-related quality of life. Am J Public Health. 1997; 87(1): 38-44. doi: 10.2105/ajph.87.1.38

45. Blaak E. Gender differences in fat metabolism. Curr Opin Clin Nutr Metab Care. 2001; 4 (6): 499-502. doi: 10.1097/00075197200111000-00006

46. Kim I, Kim HA, Seo Y Il, Song YW, Jeong JY, Kim DH. The prevalence of knee osteoarthritis in elderly community residents in Korea. J Korean Med Sci. 2010; 25(2): 293-8. doi: 10.3346/jkms.2010.25.2.293

47. Zainuddin AA, Manickam MA, Baharudin A, Selamat R, Cheong KC. Prevalence and socio-demographic determinant of overweight and obesity among Malaysian adults. Int J Public Health Res. 2016; 6(1): 661-9.

48. He X, Li Z, Tang X, Zhang L, Wang L, He Y, et al. Age- and sex-related differences in body composition in healthy subjects aged 18 to 82 years. Medicine (Baltimore). 2018; 97(25): e11152. doi: 10.1097/MD.0000000000011152

49. Howel D. Waist circumference and abdominal obesity among older adults: Patterns, prevalence and trends. PLoS One. 2012; 7(10): e48528. doi: 10.1371/journal.pone.0048528

50. Amarya S, Singh K, Sabharwal M. Changes during aging and their association with malnutrition. J Clin Gerontol Geriatr. 2015; 6(3): 78-84. doi: 10.1016/j.jcgg.2015.05.003

51. Roos EM, Arden NK. Strategies for the prevention of knee osteoarthritis. Nat Rev Rheumatol. 2016; 12(2): 92-101. doi: 10.1038/nrrheum.2015.135

52. Department of Statistics Malaysia. Population distribution and basic demographic characteristics. 2010. Population and Housing Census of Malaysia. https://www.dosm.gov.my/v1/index.php? $r=$ column/cthemeByCat\&cat=117\&bul_id=MDMxdHZj WTk1SjFzTzNkRXYzcVZjdz09\&menu_id=L0pheU43NWJwRWVSZklWdzQ4TlhUUT09\# (accessed on 23 March 2021) 